\title{
RESCATANDO AL ESCRITOR TEMÍSTOCLES AVELLA MENDOZA - ARTí́CULO
}

Luz Yenkary Peralta Jaimes 


\section{RESCUING THE WRITER TEMÍSTOCLES AVELLA MENDOZA -ARTICLE}

\section{RESUMEN}

El siguiente artículo pretende reflexionar acerca de los escritos literarios del escritor sogamoseño Temístocles Avella Mendoza, que han sido olvidados en el marco literario del municipio que lo vio nacer. Con más de dos novelas históricas y varias publicaciones de diverso carácter, Temístocles es prácticamente desconocido. Con el fin de recuperar el legado literario del escritor, se presentaran varias de sus obras célebres, como Anacoana y Los tres Pedros en la red de Inés de Hinojosa.

Palabras clave: Temístocles Avella, Anacaona, recuperación del patrimonio literario, literatura boyacense.

\section{ABSTRACT}

The following article aims to rescue and to ponder about the literary writings of Temístocles Avella Mendoza, writer born in Sogamoso, whose texts have been forgotten in the literary framework of his own town. With more than two historical novels and several publications of different character, Temístocles is practically unknown. In order to recover the literary legacy of the writer, some of his famous works will be presented, such as Anacoana and Los tres Pedros en la red de Inés de Hinojosa.

Key words: Temístocles Avella, Anacaona, recovery of literary heritage, literature from Boyacá.

\section{AUTORES}

Luz Yenkary Peralta Jaimes

Profesional en Estudios Literarios

Universidad Autónoma de Bucaramanga

Docente IPLER sede Sogamoso

Recibido: 1 de marzo 2018

Correo: yenperal@gmail.com

Aprobado: 2 de mayo 2018 


\section{INTRODUCCIÓN}

Temístocles Avella Mendoza nació el 2 de julio de 1841 en el municipio de Sogamoso, ubicado en el departamento de Boyacá. A temprana edad, comenzó a escribir y publicar sus diferentes obras en periódicos como El Estudio, El Impulsor, El Martes, El Fénix, La Juventud del Socorro, El Oasis de Medellín, El Tornillo, El Empresario de Tunja, El Iris, El Hogar, El Mosaico y La Prensa de Bogotá. Murió el 5 de abril de 1914, en Sogamoso. Su obra más reconocida fue Los Tres Pedros en la red de Inés de Hinojosa, publicada en 1864 y editada, en 1979, por la Asociación de Amigos de Sogamoso. La obra fue analizada por Peralta (2017), a nivel intertextual, comparativo y discursivo, en el artículo "Realidad y ficción en tres versiones de la historia sobre Inés de Hinojosa: aproximación intertextual".

A pesar de las diversas obras de Temístocles Avella, incluídas sus publicaciones en varios periódicos nacionales, cabe destacar que el escritor sogamoseño es desconocido a nivel tanto nacional como regional. Por ejemplo, en la Biblioteca Pública Municipal José Joaquín González Camargo, se encuentra un único ejemplar de la novela Los tres Pedros en la red de Inés de Hinojosa. Del resto de sus obras y publicaciones no se encuentra rastro alguno ni en los sitios de consulta del municipio ni en internet. Gracias a la colaboración de la directora de IPLER sede Sogamoso, Gloria Montaña, se tuvo acceso al libro Labor Intelectual presuntamente, publicado en 1915 por la Editorial UPTC - Tunja, en la ciudad de Bogotá. La otra fuente disponible es Novelas Americanas, libro publicado en 1877, en Buenos Aires, el cual recoge tres obras: La Chiriguana, de la poetisa argentina Josefina Pelliza de Sagasta; Anacoana, de Temístocles Avella y La Roca de la Viuda, del escritor peruano Ricardo Rossel. El libro se encuentra en línea gracias a la Biblioteca de la University of Texas, en colaboración con Google.

\section{RESCATANDO EL PATRIMONIO LITERARIO DE TEMÍSTOCLES}

En Labor Intelectual (1915) se exponen varios artículos, dos novelas históricas y poesías, así como su vocabulario algebraico. El libro cuenta con dos presentaciones sobre el autor, la primera del alcalde del municipio Adolfo Figueroa Avella (s.f.) y la segunda del director de la Casa de la Cultura de Sogamoso, el arquitecto Alberto Coy Montaña (s.f.). Este escribe en las primeras páginas del libro:

La Casa de la Cultura ha querido dentro de su programa de resaltar los valores sogamoseños vincularse a la conmemoración de los 150 años de nacimiento del Escritor, Historiador y Periodista Don TEMísTOCLES AVELLA MENDOZA [...] agradecemos al Alcalde de esta ciudad, doctor Adolfo Figueroa Avella, el apoyo para la reedición de "LABOR INTELECTUAL", al señor Hernando Jiménez J., el facilitarnos el original. (s.f.).

Las líneas preliminares de la reedición del libro están signadas como "B. I. C. Bogotá, abril 26 de 1915". Sin embargo, no se tiene idea de quién pueda ser la persona que firma aquellas líneas, ya que solo aparecen las iniciales B. I. C. Tampoco se encontró la fecha de la reedición del libro, solo la fecha de la primera edición, que se encuentra en la primera línea del actual párrafo. El autor de aquellas líneas, B.I.C., escribe al final (1915):

Los que lo conocimos íntimamente, pudimos apreciar la aquilatada bondad de su alma y medir los vuelos de su ingenio, tan altos, como los de muchos de los buenos escritores nacionales. Que no se le haya señalado al señor Avella el puesto que le corresponde por esas raras actividades del espíritu, quizá haya sido por el poco conocimiento que se tiene de sus obras; pero de 
seguro esta manifestación de justicia se impone: ello sólo será cuestión de tiempo.

A pesar de los esfuerzos de familiares, allegados y demás interesados en rescatar los escritos de Temístocles Avella, no se encuentra mucho de este autor en la internet, ni tampoco en bibliotecas públicas o colegios del municipio. Por ello, después de casi 177 años de su nacimiento, se pretende rescatarlo, para que, progresivamente, sus novelas y poesías salgan de nuevo a la luz. Se intenta que los escritos de Temístocles Avella Mendoza no queden en el completo olvido.

Entre los artículos de Labor Intelectual (1915), se encuentran: Marco Aurelio, que trata de un joven simpático e inteligente que pierde su fortuna apostando, pero que encuentra a una joven rica llamada Adela y el amor los une; Un rosario de Noche Buena; Ejecución de un drama, con cinco actos, contado al autor por Juan de Dios Flórez; Un capítulo de "El Carnero", trata del capítulo cinco de aquella obra, la historia de un cura y un indio; Lía y Raquel, que cuenta la historia de las hermanas del Antiguo Testamento; Las cosquillas de don Ambrosio; Escenas Bogotanas; Correspondencia Amorosa; María Ramos y el Lienzo Milagroso, crónica del siglo XVI sobre el lienzo de la Virgen en Chiquinquirá; La noche de un San Juan; Dos tradiciones; El espíritu de Franklin; Enseñanza objetiva; Los prodigios de Lorite, sobre un médico español; Los tíos de un obispo; Marubare, acerca del cacique Marubare en Santa Marta, ("hay que admitir, sin embargo, que no fue tan honrosa la muerte de Marubare, "el burro conquistador". Sus desventuras merecieron mención en los relatos de los cronistas fray Pedro Simón y Juan de Castellanos" (EI Tiempo, 20 de julio de 2005); El valle del Diablo; Catecismo republicano; Un escándalo en Tunja, historia de dos jóvenes amigos del autor. Avella (1915) agrega al final de su comentario: "entre los cronistas tunjanos de aquella época, ¿no sobrevi- virá alguno que, recortando las arandelas [...] se atreva a vaciarla en un molde estrictamente histórico?" (p.102). En el libro se incluyen dos artículos sobre el libertador Simón Bolívar: Bolívar como caudillo militar y La estrella de Bolivar.

La primera novela histórica que aparece en Labor Intelectual (1915) es El sitio de Cartagena, que trata de la batalla en Cartagena de Indias en la Independencia y los involucrados en ella. La novela cuenta con 14 capítulos y un epílogo, donde el autor reúne a dos amantes, el Capitán Jorge y la heroína Armida. La segunda novela histórica es Publio (1862), donde el autor declara que ha cambiado los nombres de los personajes y adicionado algunas fantasías debido a que los acontecimientos son recientes. Avella (1915) escribe, en las últimas líneas de la advertencia sobre el cambio: "si, pues, se pide fidelidad a la historia, concédase a la novela su ficción y disfraz, conservando sí, en éste y aquella, la verosimilitud" (p.134). La novela cuenta con 18 capítulos sobre dos amigos, Publio y Luis y Elisa, amante de Publio.

Después de las novelas históricas se encuentra el Vocabulario algebraico, formado por palabras en clave: abrevia las palabras para luego combinarlas $y$ formar frases u oraciones con estás. A continuación, se presenta un fragmento de los signos y las claves, luego de las combinaciones de signos y su respectiva traducción. Avella (1915) construye el siguiente vocabulario conformado por vocales signos y consonantes:

De las poesías en Labor intelectual (1915), se encuentran: Travesuras, Andrés Bello, La vida humana, Las dos flores, entre otras. Algunos de los poemas del libro hablan de personajes importantes, como Andrés Bello, otros son de temática amorosa, otros sobre la tierra en la que nació y otros de temática histórica. 


\begin{tabular}{|l|l|}
\hline \multicolumn{1}{|c|}{ Signos } & \multicolumn{1}{c|}{ Clave } \\
\hline A k & Acá (adverbio) \\
\hline A c i t & Aceite \\
\hline A + & Amas (inflexión de amar) \\
\hline B b & Bebe (inflexión de beber) \\
\hline K b & Cabe \\
\hline K d t & Cadete \\
\hline Ch p & Chepe (alteración nombre propio) \\
\hline D+ & Demás \\
\hline$+z$ & Maceta \\
\hline$-k$ b & Menoscabe \\
\hline O q p & Ocupe (inflexión de ocupar) \\
\hline U L & Huele (pp. 199 - 208) \\
\hline Combinaciones de Signos & \\
\hline P k 2 d P p 8 a & Pecados de Pepe Ochoa \\
\hline D g ak, s +o & Deje acá ese mazo \\
\hline E ch + a c it & Eche más aceite y coma \\
\hline
\end{tabular}

Además de los escritos de Temístocles Avella reunidos en Labor Intelectual (1915), se encuentran varios dramas, como Jaramillo afirma (2012): “Gustavo III, Las dos huérfanas, trabajos históricos de carácter biográfico sobre personajes célebres chibchas, ibéricos e hispanoamericanos, antiguos y contemporáneos" (p.10). Se encuentra también la novela histórica Anacoana, publicada en 1877 en el libro Novelas Americanas. La historia inicia en diciembre de 1493 en las islas del archipiélago Jardines de la Reina, con el conquistador español Alonso de Ojeda y un cacique de la región. Anacoana era la esposa del aquel cacique, ostentaba los lujos y comodidades que una mujer de su rango podía permitirse. Avella (1877) la describe de la siguiente manera:

talle airoso, ojos negros, húmedos y grandes, mirada abrasadora y capaz de conmover el frío mármol: hé ahí el exterior de aquella mujer admirable. En las palpitaciones de su seno se creia ver saltar un corazon de fuego, y en su erguida y limpia frente reverberaban los rayos de una imajinacion de sibila. Su voz era un canto; su sonrisa era néctar, aroma y luz; su alma 
debía ser un himno viviente. Se comprendia, al verla, que era poetisa: se veía en ella la inspiración ántes de oir sus versos.

Tal era Anacoana. (p.39. Se respetan la puntuación y ortografía originales).

Anacoana, además de profetisa, es descrita como una mujer de porte e inteligencia, que componía poesía y canciones para su hija Corima. En Los tres Pedros en la red de Inés de Hinojosa, novela también histórica, Avella describe a una mujer de porte e inteligencia, aunque el carácter de ambas diste bastante. Anacoana es una madre amorosa que permite la unión de su joven hija con el español Francisco de Guevara, gobernador de la ciudad Isabela, pues ambos jóvenes se profesaban un amor profundo y verdadero.

Por otra parte, Guevara tiene un rival, cuyas intenciones al principio son encarcelarlo y enviarlo a España para reemplazarlo como gobernador de la ciudad, pero los habitantes y soldados de Isabela estaban a favor del joven Francisco de Guevara. El español decide irse a vivir con su amada y la madre de esta, dejando a Roldan como gobernador. Sin embargo, este, no satisfecho con tener el puesto de gobernador, le pide a Anacoana organizar un banquete con los demás caciques de la región, con el objetivo de atacarlos y robarles el oro que llevan en su vestimenta.

Después de un entretenido espectáculo con armas y caballos, Roldan y sus soldados van contra la multitud, asesinándolos. El palacio de Anacoana era de madera, lo que facilitó que el fuego se propagara. Anacoana murió cantando, implorando el perdón para los autores de tan atroz crimen.

Alonso de Ojeda va con el cacique hacia España, pero, debido a una tormenta, el barco en el que viajaban es destruido, siendo los únicos sobrevivientes
Ojeda y dos pilotos. El español regresó de nuevo al archipiélago, pero el fantasma del cacique lo persigue. Al llegar al bohío se da cuenta de las atrocidades de Roldan y se lamenta eternamente por lo sucedido con el cacique arrestado y los demás muertos en la masacre.

Se resalta el enfoque de Temístocles en la novela Anacoana, pues el autor se empeña en mostrar la maldad española, en este caso con Alonso de Ojeda y el gobernador Roldan que, por ambicioso y vengativo, ordenó matar a los caciques de la región. El escritor tenía una noción bastante clara de la ideología española: "se sabe que el oro el único Dios de los conquistadores: de ahí la venalidad con que obraban estos soldados y las atrocidades de que fueron capaces" (Avella, 1877, p.536).

Se aclara que la Anacoana de Temístocles Avella tiene relación con la famosa cacica Anacaona de la isla La Española, inspiración de la canción de Cheo Feliciano titulada con el nombre de la india taína. La Anacaona que fue cacica era inteligente, bella y dada al arte poético, gobernaba en su territorio Jaragua, pero no sentía simpatía hacia los españoles como el personaje de Anacoana que describe Avella. Ortega (2017) afirma:

Fue entonces cuando convenció a su esposo Caonabo para exterminar a los invasores e inicio la lucha para defender los derechos de su gente. Mas esto de poco sirvió, pues cuando los españoles se dieron cuenta de sus peligrosas intenciones le tendieron una emboscada encabezada por el gobernador Nicolás de Ovando, quien anunció una visita pacífica a la mandataria taína. Los españoles aprovecharon la ocasión para prenderle fuego a toda la aldea. Muy pocos aborígenes lograron sobrevivir la mencionada tragedia. El gobernador se 
obsesionó con la cacique considerándola como una amenaza y ordenó a una exhaustiva búsqueda por toda la región. Fue condenada a morir en la horca en medio de una plaza pública.

El carácter revolucionario de la Anacaona histórica encaja mejor con el carácter de Inés de Hinojosa, que con el de Anacoana. La lucha en el interior de Inés de Hinojosa era la mezcla de sangre española e indígena, por eso Temístocles la describe como una mujer perversa y desalmada, autora intelectual de los asesinatos de sus dos esposos Pedro de Ávila y Jorge Voto. Pero la Anacoana que retrata en la novela era una mujer más bien pasiva, aunque inteligente, que solamente pide que salven a su hija del incendio y no conjura nada en contra de los españoles, antes bien, pide que se les perdone por sus actos.

De la novela Daniel Sikles no se tienen datos que indiquen fecha de publicación, o si tiene relación con el personaje histórico Daniel Sickles, político y soldado norteamericano, o alguna temática relacionada. Jaramillo (2012) afirma:

Sus Cartas de un viajero comprenden 138 páginas del libro editado en 1869 por don Nicolás Pontón, con el título de Semana literaria de El Hogar. El autor da en ellas cuenta de su viaje, efectuando el año de 1868. El relato es sencillo, como ideado solo para informar a su familia, con absoluta fidelidad, de los percances de la correría y de las cosas más notables que vio. La primera carta está fechada en Ronda, el 22 de Julio de 1868 [...] se afianzó su creación literaria, ya que conoció de primera mano los estilos literarios imperantes en el antiguo continente. (p.10).
De la novela Los tres Pedros en la red de Inés de Hinojosa no se profundizará demasiado en el presente artículo. Avella toma la historia de la mestiza Inés de Hinojosa que aparece en el capítulo X de El Carnero y la convierte en una historia romántica, incluyendo un personaje para lograr una historia de amor entre la sobrina de Inés de Hinojosa y el hijo del primer marido de la mestiza. La novela se enmarca en la Tunja colonial, donde los indios todavía eran esclavizados por los españoles, mostrando así la malicia de estos, no solo respecto a los indígenas, sino también a los de su misma procedencia, pues el bailarín y músico español Jorge Voto, siendo amante de Inés de Hinojosa, asesina al esposa de esta, Pedro de Ávila, para luego convertirse en su esposo. Sin embargo, Voto es asesinado, a su vez, por el segundo amante de la mestiza, el encomendero Pedro Bravo de Rivera.

\section{¿POR QUÉ TRAER DE NUEVO A LA LUZ LOS ESCRITOS DE TEMÍSTOCLES AVELLA?}

El legado literario de Avella es amplio y variado, incluyendo trabajos históricos y literarios que retratan la cultura de su época, como el caso de la novela $\mathrm{Pu}$ blio. Otros rescatan pasajes de cronistas del pasado, como Los tres Pedros en la red de Inés de Hinojosa y otros son específicamente históricos, combinando realidad y ficción, como El Sitio de Cartagena.

En sus novelas, Temístocles Avella Mendoza se enfocó en el pasado, sobretodo en la época de conquista y colonia en América. Muestra, particularmente, su pensamiento respecto a los personajes y hechos históricos que marcaron nuestra sociedad, por ejemplo, al señalar la naturaleza de los conquistadores españoles y el daño que causaron en los aborígenes del continente. Esto se ve, especialmente, en la novela Anacoana. La quema del palacio de la indígena recuerda la quema del Templo del Sol en Sogamoso, provocada por la codicia de los españoles. 
Es una pena que otro tanto de las obras literarias y periodísticas de Temístocles Avella permanezcan perdidas en bibliotecas, archivos o cartas enviadas por el autor a familiares y amigos. Es también una pena que su nombre esté olvidado por los habitantes del municipio de Sogamoso, pues las obras de Temístocles Avella poseen una belleza narrativa que resalta su estilo romántico e histórico. Jaramillo (2012) afirma:

Además de infatigable periodista fue un notable poeta, historiador e investigador. En su afán de superación personal viajó a Europa para estudiar las diferentes culturas y así ampliar sus conocimientos; todas esas experiencias quedaron grabadas en sus "Cartas de un viajero" que aparecieron en otros periódicos del país. Leía en francés, inglés e italiano. Luchó por infundir una sana educación, sólida y amplia a la colectividad del pueblo. (p.9).

A juicio personal, Temístocles Avella merece un reconocimiento por su labor intelectual, periodística, histórica y literaria, que trae una visión diferente del pasado, combinando la historia con la fantasía, el amor y el humor. Como dice Jaramillo en la cita anterior, Temístocles Avella no solo puede ser reconocido por su legado literario, también por su ánimo de enseñanza y aprendizaje, al que distintas adversidades, como quedar huérfano a temprana edad, no impidieron convertirse en el hombre íntegro que llegó a ser. Se espera que se esparsan sus escritos, o al menos cierta información sobre ellos, y que muchas más mentes lean, se deleiten con las obras del autor sogamoseño y lo reconozcan por su dedicación a la historia y la literatura.

\section{REFERENCIAS}

Avella, T. (1877). Anacoana. En Novelas Americanas. Buenos Aires. Recuperado de: https://archive.org/ details/bub_gb_ZfJUAAAAMAAJ

Avella, T. (1915). Labor Intelectual. Bogotá: Editorial UPTC - Tunja.

Avella, T. (1979). Los Tres Pedros en la red de Inés de Hinojosa. Asociación de Amigos de Sogamoso.

Coy, A. (s.f.). Presentación. En Avella, T. (1915). Labor Intelectual. Bogotá: Editorial UPTC - Tunja.

El Tiempo. (20 de julio, 2005). "Los otros tres samarios heroicos" Recuperado de: http://www.eltiempo. com/archivo/documento/MAM-1956462

Jaramillo, J. (2012). "Jorge Voto como héroe romántico en la obra de Temístocles Avella Mendoza Los tres pedros en la red de Inés de Hinojosa". Tesis de la Licenciatura en Español y Literatura, no publicada. Universidad Tecnológica de Pereira. Recuperado de: http://repositorio.utp.edu.co/dspace/bitstream/ handle/11059/3063/86344J37.pdf;sequence=1

Ortega, B. (9 de agosto, 2017). Anacaona, la defensora del pueblo taíno. Recuperado de:

http://www.conectate.com.do/articulo/ anacaona-biografia-republica-dominicana/

Peralta, J. (2017). "Realidad y ficción en tres versiones de la historia sobre Inés de Hinojosa: aproximación intertextual - artículo". En: Revista La Tercera Orilla, 19. 32-41 